\title{
A call for video images: medicine in real time
}

\section{Eric Wooltorton}

The uses to which photographs may be put are so numerous that we anticipate for it a very foremost place among the scientific appliances of the age. ${ }^{1}$

$\mathrm{O}$ f photography's many applications, medical documentation was among the first. Despite the technical limitations of early photographic processes, pioneers of the medium saw an exciting potential not only to represent human anatomy and physiognomy with greater objectivity than an artist's rendering, but also to record phenomena that the human retina cannot register. When it was discovered in the 1850s that electric spark illumination had the optical effect of "freezing" motion, ways were sought to use the essentially static medium of photography to capture animate nature. In 1865 the heartbeat of a tortoise was recorded by means of a double exposure on film. In the 1870s and 1880s a fascination with animal and human locomotion led to experiments in "chronophotography" - rapid sequential exposures that recorded details of movement that the eye cannot grasp - whose practical applications included ergonomic studies and training manuals for physical education. By the 1890s, with the advent of motion pictures, it became possible not only to record the form of living motion but to replicate its duration. ${ }^{2}$

Physicians of that time could not have imagined the array of medical devices their modern-day counterparts have at their disposal to create moving images of human physiology, behaviour and disease. Through video cameras, scopes and scanners of all sorts our patients and their various parts are routinely captured in their animate reality.

New communication technologies have also entered the picture, allowing medical images to be disseminated electronically for educational and clinical purposes. Data transmission has become fast and reliable, and data storage cheap. The "digital revolution" of the last decade has made it possible to transmit texts, images, recordings and video clips to colleagues around the world, and, more dramatically, has made long-distance radiology $y^{3}$ and even telesurgery possible. ${ }^{4}$

In recent months $C M A 7$ has experimented with running brief video clips as enhancements to the electronic edition of the journal. In January 2004, the proper application of personal protective equipment was demonstrated. ${ }^{5}$ In the online version of the June 8,2004 , issue, an echocardiogram was at- tached demonstrating a positive bubble study and a patent foramen ovale. ${ }^{6}$ And in this issue we have an animated illustration of the immunologic basis of psoriasis, ${ }^{7}$ along with video clips that amplify the content of the methods section of a research paper. ${ }^{8}$ In each of these cases, moving images serve not only to communicate facts, but to communicate them more effectively: to demonstrate rather than merely describe.

We have made calls for medical images before (see page 1930). ${ }^{9}$ Now we invite authors to send us video clips to accompany their articles. We are best equipped to post, and readers are best able to download, brief clips sent to us on compact disk in commonly used formats (MPEG, AVI or MOV). Files less than 10 megabytes in size are recommended. A signed patient consent form allowing us to publish details or images related to a case should accompany the submission. More detailed instructions for video submissions (as well as publication consent forms) are available under "Instructions for authors" at www.cmaj.ca. We invite you to contribute to $C M A \mathcal{A}$, the animated version.

Eric Wooltorton is an Associate Editor with CMA7.

Competing interests: None declared.

\section{References}

1. The Photographic News, 1865 Jan 6. Cited in Ewing WA. The body photographs of the human form. San Francisco: Chronicle Books; 1994. p. 106.

2. Braun M. The expanded present: photographing movement. In: Beauty of another order: photography in science. New Haven and London: Yale University Press in association with the National Gallery of Canada; 1997. p. 150-85.

3. Lougheed T. Radiologists get that long distance feeling. CMAf 2004;170(10):1523

4. O'Meara D. Robot arms to revolutionize neurosurgery - and more. CMA7 2004;170(11):1654.

5. Hutcheon DJ. Prehospital intubation and SARS [letter]. CMAJ 2004;170(1):19.

6. Dowlatshahi D, Hogan MJ, Sharma M, Wherrett CG. A 32-year-old man with acute bilateral leg weakness following recreational diving. CMAJ 2004;170(12):1792.

7. Walsh SRA, Shear NH. Psoriasis and the new biologic agents: interrupting a T-AP dance. CMA7 2004;170(13):1933-41.

8. Woo JKH, Ghorayeb SH, Lee CK, Sangha H, Richter S. Effect of patient socioeconomic status on perceptions of first- and second-year medical students. CMA7 170(13):1915-9.

9. Wooltorton E. Launching a new journal page: Clinical Vistas [editorial]. CMA7 2001;165(9):1221-2.

Correspondence to: Dr. Eric Wooltorton, 1867 Alta Vista Dr. Ottawa ON K1G 3Y6; fax 613 565-5471;

eric.wooltorton@cma.ca 